Prof. Dr. Jovan Pejkovski

Faculty of Philosophy - Skopje

Head of the Institute for Social Work and Social Policy "Mother Theresa"

Skopje, Republic of Macedonia

\title{
STRATEGIES AND NEW MODELS FOR SOCIAL DEVELOPMENT
}

UDK: 304-027.511(497.7)

Strategic planning is the process of formulating and implementing strategies with which the organizations and the institutions are adjusted and influenced on the changes in the environment.

Understanding of the future and the need for strategic determination of the conditions and possibilities for its achievement is crucial question of each society.

Creating a strategy cannot be understood as a magic solution to the problems because it is a way to deal with the problems and risks that will appear in a structured way. Creating strategy represents a new way of thinking, and accordingly creates new skills to be able to carry out the process. But it also must be flexible and adapt to the characteristics and specifications of each organization.

With including of the key elements of the strategic planning process successful strategic prediction is achieved aimed at decisionmaking procedure related to the organization of the system and the environment in the future.

The impacts of globalization but also many international organizations and funds will imply the needs for the preparation of strategies that are derived from strategic planning. Organizations, institutions, whether public or private, should be developed in subjects that 
can easily and quickly adapt to changes in the internal or external environment.

In the current postrecesion stage of living of the societies the strategy comes as a means of seeking a response to the crisis and out of it to further social development. Strategy becomes the basis for mobilization of social resources and to offer possible exit paths that strengthen cohesion. They have to offer changes primarily in the area of understanding of social processes.

It requires changes in education and supply of knowledge as people cope with the effects of the recession. There is no magic solution. All are slowly but means activation in a particular direction, and once the whole strategy are set the action can be expected with effects and developmental outcomes.

What are the possible courses of action in response to the current models of development that have limited achievements? Primarily relates to the offering of educational strategies which will not be dogmatic and endless restrictions but with a creative approach and freedom of expression of individuals. They not to be put in a frame but with overcoming of the barriers to request creativity in the process of solving the problems.

Current development models are facing with major challenges and suffered from the consequences of the global economic crisis. The measures and the implement strategies do not offer solutions for sustainable development in the long term.

What could be offered for the creation of new strategies that can solve economic and social problems? Are economic systems having the potentials to produce new energy and new orientation to develop a level of development that can solve social problems? How to reduce poverty and unemployment and to create conditions for social inclusion of many socially excluded citizens?

Interventions of states are prerequisites for organizing and operating the system. Does every state have capacity in the long term to 
implement a new model of development or new strategies for motivating economic and social systems?

All these questions require answers that neither easy nor simple. Also the question arises: What is the ability of a society to ensure the welfare of all members and to decrease inequality to a minimum to avoid the marginalization of certain groups. Is the modern crisis brings social system in the condition of permanent producing of social problems?

What are the funds allocated for solving social problems, are they sufficient and sustainable in the long run, and in the same time to not disrupt the basic motivational elements of working citizens?

What strategy is needed to re-shaping the welfare state? Should new Canceller Bismarck will appear or similar historical gin of modern aspect to propose solutions that balance between growing rich minority and rapidly growing poor majority?

What strategy should be created to ensure social justice and social cohesion in the same time with democratic structure that realizes social development? How to exceed divisions and inequalities in societies as social differences create antagonisms, and thus long-term instability and unfairness?

What concepts can be offered which is a mission of the science as a challenge and as a driving force in the mental perception of all these issues and in proposing possible solutions and answers?

Whether strategies cannot be operationalized and realized because of an objective social separation or due to the inability of the new rearrangement of social welfare. The theses of limitation of the resources when they should be shifted to social goals are relative due to the enormous polarization between poor and rich. The crisis in the past years whose consequences still are present shows that the rich are becoming richer and the poor grow in pauperizated army and homeless people. Is this result of neoliberal strategy for the role of the individual and the elite in the society? 
Is the neoliberal concept that continuously generates differences will have to be corrected by neokeyneziant concept for greater state role in the distribution of economic resources? Or will seek a compromise between these two conflicting concepts.

The strengthening of entrepreneurial activities and especially social entrepreneurship requires setting an environment and support as necessary conditions for freedom of expression, to open businesses and thus to greater employment and for solving social problems.

Are there any new visions of progress and prosperity based on economic resources or necessary changes in the use of human resources and a greater recognition of their role in the creation of values?

Capital plays its role in fertilization and in gaining profit but behind that activity of capital standing man, worker, whose exploitation must be balanced as precondition to maintain social balance. That's the main pillar for building of social cohesion and strengthening the conditions for living and working of the people.

Intergenerational solidarity and introducing the concept of active aging require changing patterns of living and the paradigms that until now were built. The beginnings of these concepts should start from the earliest age, at which, each individual must become aware that life is a nontransferable and that any building of the future start from birth to old age.

Is the society gives equal chances to all or the chances for future generations will be fight from today generations. It is a matter of social order, democratic governance and the changes that can range from moderate to radical changes in the social relations.

Social progress requires closer review of the social and economic inequality, the sources that generate them and new approaches and measures for their removal.

Otherwise the social and environmental costs will increase and thus the unfavourable impact of the environment with decreasing of the developmental potentials and performances. 
If the concepts of social balancing will be strengthening it can lead to social cohesion which should be ensure that all stakeholders will participate and cooperate fully in the development of democratic and sustainable processes? It is not acceptable some citizens to live at the expense of others but is should be social arrangement in which everyone will have possibilities to enjoy the results of its own engagements and arrangements which are available.

The conflicts that can be expected are more result of divisions that cause inequality in the distribution of wealth, ethnic and cultural diversity and the different ways in which environmental conditions affect people's lives.

SEE countries need better cooperation and new strategies how to integrate their capabilities and to enhance their development. They need infrastructure connections and interconnection plugs, power relationships and liberalized free trade without border restrictions. They need integrated development as a pillar for achieving their competitive advantages at the appropriate level which was destroyed due to historical issues whose consequences are still present. They need investments at regional level that will create preconditions for their development and cooperation.

This new model of cooperation can establish new connections and interest in expanding their economic integration as the basis of their better social and economic development. An integrated development model can offer a better chance for the SEE countries and their presence in more markets and in the EU and beyond.

The new strategy for cooperation favoured by the European institutions is based on the need for reinvestment in social rights and builds a cohesive society, acceptance of responsibility for social problems, strengthening of democratic decision making and expanding social dialogue and civic engagement in building a stable and secure future of the region.

Beside for European states these have special meaning for the countries of the region of Southeast Europe which must overcome their 
age-old divisions and antagonisms in order to accelerate its growth and progress towards EU.

Social rights have played a significant role in European growth and differentiation of Europe from other regions of the world. European model of social rights has served to create and maintain social cohesion and social solidarity, although globalization and other developments press for this model.

The emergence of the examples of a divided society in which a growing number of people facing barriers to the full enjoyment of certain rights that depend on wages and other public services, together with growing inequalities between rich and poor is one of the biggest challenges for social cohesion in Europe.

Improvements of the access to social rights through a wide range of offers in different areas are examples of overcoming obstacles and social exclusion.

These positive examples could be followed as a good practice and to be implemented in the SEE countries.

The adaptation to the changes is essential in the modern world where the constantly emerging new opportunities and new constraints. It must not allow the socially excluded and poor to be disabled in social life. In contrary the strategic orientation and concepts are looking to invest in a cohesive society in which everyone will have an opportunity to improve the quality of life for all members of society, including the poorest, with respect to the values of their community.

The affiliation to the community is strengthening the creative forces and encourages individuals to hold accountable for their own development, to participate in its shaping on the long term and to suggest priorities for social development. In this process there are always differences in interests and objectives of the development but the main strategic objectives such as the fight against poverty, providing welfare for all, ensuring sustainable development in a pluralist society, leading to social cohesion remain the same. It is perceived by shaping the 
institutional programs that are made for the purpose of development. Without these programs the developmental process cannot be run in the short medium and long term, it must express the specific needs and expectations of citizens.

What can the government in each state to offer in creating politics? It primarily refers to increasing transparency in the decision-making processes and goals as well as the perception of the results of certain policies. In modern information lifestyle events and deciding quickly spread and disseminate therefore the greater participation of citizens, associations, organizations and companies can contribute to the creation of policies and strategies aligned growth and development, especially for social development.

If certain policies and strategies do not give the expected results they have to be quickly changed and adapted to the real needs and goals. Just so the government become closer to the modern concept of the welfare state in which interests are multidimensional and confrontational you can harmonize in interest of the progress of the people.

Does this seem very idealistic explanation of the things? The models and estimates of the development with great precision and using numerous variables and indicators of the effects of development could be prepared. But basically it must be reduced to building a stable developmental model which if not properly formed can start with strengthening of antagonisms and lead to social destruction of the system, or request a new model and new concepts of development.

The monitoring of indicators of well-being and using the methodological approach that involves citizens in defining the criteria for growth and development can make very realistic simulations and strategically to determine the future dynamics to social living.

What are the contribution and the need to seek new strategies and development models? This refers primarily to create a new vision for economic and social development and creation of jobs that reduce poverty and social exclusion. This leads to long-term balance of decent working conditions, harmonization of work commitments, family and personal life, 
use of resources and recognition and respect for local communities and economic utilities.

Creating of jobs support and strengthen the social ties, solidarity and build new trends in terms of social capital as an unbreakable bond of modern life.

The achievements and strategies of social work and social politics are always important aspects of every society. The commitment is to educate young people who are a key element for the future of society. Also the commitment is through introducing various developmental directions and patterns of growth and development to educate youth and gradually encourage their commitment as citizens, the development of society and its institutions that affect development processes.

Young people should be actively encouraged to use their knowledge, resources and facilities, and to engage in entrepreneurial activities as well as in finding common solutions and plans for solving social problems, and to achieve social development.

Otherwise, the lack of perspective discourages youth makes them to seek the solutions in other countries and regions and do not accept responsibility for the development failures that inherit. In young people the state must invest, students and future graduates Masters PhD should be a priority and the society as a whole must support sustainable employment and personal fulfilment, family life and social commitment.

Europe is aging, and also the Republic of Macedonia. All these situations open questions about pension funds and insurance, including intergeneration solidarity. The long-term sustainability of pension funds must be ensuring that requires the strengthening of integration and solidarity between generations. The concept of "active aging" is a concept of the future and could solve the problems that arise as a result of aging.

It opens dilemmas must ensure about responsibility for the future growth and development. Are only the strategies and concepts can express the vision pursued for states and citizens? In fact anyone has a certain level of responsibility but mostly emphasized responsibility of the highest 
management level who must have the vision and knowledge of strategic planning and the and action plans for their implementation. In this way, by proposing and implementing specific policies and actions in favour of social cohesion, which are made in collaboration with various sectors and with harmonization of social relations the development become possible and can improve developmental performance.

Citizens and communities need to develop awareness that they are actors of the changes. Their interest should be expressed not only in the initial stages of policy making but also in its implementation especially when it comes to adopting regulations that reduce social rights. Their performance often is blocked by media and do not have enough information about the possible changes that are made. Therefore requesting representation in civil organizations and creation of future plans and strategies in which they can express their interests is a method of influence on the direction of policy, especially its implementation. Forms and structures of representation of citizens encourage greater participation of all members of society, including vulnerable groups, which must comply with the principle of positive attitude towards these groups in the regulations.

This creates conditions for participation in building a common vision for the welfare and future of young generations. What will be the development priorities depends of the expressed requirements. Organized requirements for creating equal social opportunities, particularly in relation to the entrance of the labour market and to promote the market impact can have impact of the adoption of specific policies to encourage greater employment and support entrepreneurial activities.

The searches of solutions for social mobility and for support of youth in postrecesion stages of are particularly important strategic goals for the development of policies for greater engagement of youth. This avoids opportunities for antisocial and delinquent behaviours that are common in terms of decreased economic activities, poverty and unemployment. 
Digital communications, social networks are strengthening the role of social capital particularly among young people. Strategic approach to these new phenomena by strengthening family values, social relations and solidarity between young and old or strengthening of intergenerational solidarity is indispensable strategy. This is particularly important in countries where the population is aging. In these countries the sustainability of social security systems and social security is limited or reduced because it is indispensable change for resources that allowed functioning of these systems.

Without real investment is not possible realization of dynamic growth and development, and thus to solve the growing social demands and tensions. Investments are needed in the real sector restructuring to the final products and promoting their markets. Strategy to support projects and investments in key areas such as infrastructure, education, research and innovation become a prerequisite for dynamic growth and development.

Also there are systemic measures which must put into operation the investment process by removing the various financial and nonfinancial barriers to investment. This applies especially to small and medium enterprises, as well as long-term investments, which could multiply in creating additional effects in consumption, and thus the opening of new jobs and solve social problems. It leads to the strengthening of competition and enhance knowledge, human capital and physical infrastructure necessary for development.

Processes and strategies are not only national or European because they become universal processes as a result of globalism and similarity of social politics which are implemented. As a result of differences the framework and strategies of these policies must recognize the specificity in every state with enough flexibility before policymakers to tackle situations that are unknown in the context of future social development.

The strategic approach means the process of building a shared responsibility for future policies and actions of the actors in social life. The selection of acceptable priorities in terms of well-being for all means 
to share the burden of obligations which are created from those who need to be helped. 


\section{References}

A. and Sheffrin, S. M. (2003). Economics: Principles in action. Pearson Prentice Hall, Upper Saddle River, New Jersey. 471pgs.

R. Conteras, "How the Concept of Development Got Started" University of Iowa Center for International Finance and Development E-Book [1]

Schumpeter, Joseph \& Backhaus, Ursula, 2003. The Theory of Economic Development. In Joseph Alois Schumpeter. pp. 61-116. Available at: http://dx.doi.org/10.1007/0-306-48082-4_3 [Accessed October 19, 2009].

See Michael Todaro and Stephen C. Smith, "Economic Development 11th Edition"., Pearson Education and Addison-Wesley (2011).

Jayati Gosh (January 2013). "Too much of the same". D+C Development and Cooperation/ dandc.eu.

Firzli, M. Nicolas J. (September 2013). "Transportation Infrastructure and Country Attractiveness". Revue Analyse Financière (Paris). Retrieved 26 April 2014.

M. Nicolas J. Firzli: '2014 LTI Rome Conference: Infrastructure-Driven Development to Conjure Away the EU Malaise?', Revue Analyse Financière, Q1 2015 - Issue $N^{\circ} 54$ 